\title{
Influence of Stress States on Forming Hybrid Parts with Sheet Metal and Additively Manufactured Element
}

\author{
Jan Hafenecker, Thomas Papke, and Marion Merklein
}

\author{
Submitted: 18 December 2020 / Revised: 15 February 2021 / Accepted: 13 March 2021 / Published online: 5 April 2021
}

\begin{abstract}
Hybrid parts with additively manufactured elements (AME) combine the advantages of two or more manufacturing processes, e.g., forming and additive manufacturing (AM), and thus offer a solution to the increasing demands of industrial trends such as personalized mass production. Despite their advantageous properties, research in this field still lacks in clear classification and process interactions. Due to the strong influence of the AME on the formability of hybrid parts, the combination of laser-based powder bed fusion (PBF-LB) with subsequent sheet metal forming is examined in this paper. Therefore, cylindrical functional elements are built up on sheet metal and the resulting hybrid components are subsequently formed. Common forming processes such as bending, stretch forming and deep drawing are compared in regard to the different stress states. The results show a reduction in formability for hybrid components compared to conventional sheet metal materials. Reasons found are geometrical properties, gradients of mechanical properties and induced stresses. Consequently, requirements for the additive manufacturing process regarding a subsequent forming process are outlined. Namely, the gradient of mechanical properties should be smoothened, residual stresses kept low and the design of AMEs should avoid stress concentration.
\end{abstract}

Keywords additive manufacturing, hybrid material, modelling and simulation, sheet metal formability, titanium

\section{Introduction}

Additive manufacturing (AM) technologies are well known for their tool-less layer-based process, thus enabling great possibilities in terms of geometric freedom and flexibility (Ref 1). On the other hand, AM technologies still lack in terms of short process time and reproducible part quality (Ref 2). The opposite applies to forming technologies, which are well suited to produce the same part with reproducibility and short cycle times (Ref 3). The combination of both production technologies leads to hybrid parts (Fig. 1) and the advantages of both processes are used while individual disadvantages can be compensated (Ref 4). This combination has high potential to fulfil the needs created by industrial trends like mass customization by manufacturing personalized products in high volumes (Ref 5). Due to the complex interactions between the process technologies, recent studies focus on the influence of AM structures on forming operations. Thus, in this paper, the influence of different stress states on hybrid parts, which consist of sheet metal and AMEs is investigated.

This invited article is part of a special topical focus in the Journal of Materials Engineering and Performance on Additive Manufacturing. The issue was organized by Dr. William Frazier, Pilgrim Consulting, LLC; Mr. Rick Russell, NASA; Dr. Yan Lu, NIST; Dr. Brandon D. Ribic, America Makes; and Caroline Vail, NSWC Carderock.

Jan Hafenecker, Thomas Papke, and Marion Merklein, Institute of Manufacturing Technology, Friedrich-Alexander University ErlangenNuremberg, Erlangen, Germany. Contact e-mail: jan.hafenecker@fau.de.
Because of its wide range of usage, the term hybrid is classified in (Ref 6) into three different categories. Those are hybrid machines, processes and materials (Ref 6). Hybrid machines include two or more processes within one setup, e.g., combinations of milling and turning machines or directed energy deposition (DED) and machining (Ref 6). Concerning hybrid processes, different definitions exist with their own specifications. In (Ref 7), a process is only called hybrid if the combination of two or more processes, tools or energy sources is used at the same time and leads to a significant improvement of process performance. Furthermore, hybrid processes are divided into a) the application of process mechanisms, which are conventionally performed in sequence, e.g., hot stamping, b) the combination of different energy sources or tools, which include b1) assisted processes, e.g., laser-assisted turning and b2) mixed processes, e.g., curved profile extrusion (Ref 7). A similar definition is found in (Ref 8), whereas the simultaneous usage of processes can also be used to improve the part quality. In (Ref 6), the definition of hybrid additive manufacturing (AM) processes is stated. The term hybrid AM process is used, if $\mathrm{AM}$ is combined with at least one additional process to increase the parts quality (Ref 6). Unlike before mentioned, the single processes can be performed in sequence and the primary process rarely influences the secondary one (Ref 6). An improvement of part quality is the consensus of Ashby's (Ref 9) definition of hybrid materials. Hybrid materials consisting of two or more materials have properties, which the components on their own do not have (Ref 9). Famous and widely used examples are sandwich structures, segmented parts and those reinforced by lattice structures and fibers (Ref 9). A similar definition is found in (Ref 10) where two components have to be blended on molecular scale to create a new function or structure. In this research, the definition according to (Ref 6) is used, where hybrid parts can be made of one material, but include different structures, e.g., granular microstructure, possibly serving different functions. 
The combination of AM and machining is widely used and can be found in hybrid machines (Ref 6). A more recent approach is the combination of AM and forming technologies. The combination of additive manufacturing and forming creates parts of the same material with different microstructures. There are many ways to manufacture hybrid parts, as there are different forming operations that can be combined with different AM processes.

\subsection{Additive Manufacturing and Bulk Metal Forming}

The feasibility of combining wire arc additive manufacturing (WAAM) with hot forging is proven in (Ref 11) for EN-AW 6082. Furthermore, it is not only possible to manufacture a turbine blade made of Ti-6Al-4V with this combination of processes, but the properties of the hybrid part are comparable to a conventionally made one (Ref 12). Additionally, the reduced flow stresses of additively manufactured material compared to conventional one lead to a reduction of tool load and wear (Ref 12). Similar results are found for Inconel 718 in (Ref 13). Instead of WAAM, directed energy deposition is used to create pre-forms to be forged as well (Ref 13). The additively manufactured pre-forms have a hot formability comparable to conventional wrought material, but due to the geometric freedom of the AM process, forms close to the final geometry can be produced, thus reducing the amount of forging steps and tools (Ref 13). For Ti-6Al-4V, the hot formability of parts made by directed energy deposition and laser-based powder bed fusion (PBF-LB) is investigated in (Ref 14). Again, the additively manufactured pre-forms are suited to be hot forged. This results in reduced amount of forging steps, tool load and wear but also increases the material efficiency (Ref 14). Conventionally, Ti-6Al-4V is forged with rather simple geometries and finished by milling with high chip volumes up to almost $90 \%$ (Ref 15), which makes the process even less efficient because of titanium's low machinability (Ref 16).

\subsection{Additive Manufacturing and Sheet Metal Forming}

While the combination of bulk metal forming and AM is promising for special applications, hybrid parts made of sheet metal and AM structures have a great potential. Investigations regarding the formability of a sheet metal body with a layer manufactured by DED to increase the stiffness is shown in (Ref 17). The hybrid part is still formable after the DED process, but the heat of the AM process leads to a softening in the sheet body due to grain coarsening for the investigated micro-alloyed steel (Ref 17). The heat input of the AM process can also decrease the formability of the parts made of aluminum alloys
(Ref 18). In case of (Ref 19), a local height adjustment performed with DED is used to increase the stiffness while still being formable. The biggest drawback of DED is the resulting surface roughness and geometrical imprecision (Ref 20). Thus, processes like PBF are preferable. Electron beam (EB), as it is used in (Ref 21, 22), is one of the possible beam sources for PBF. Advantageous process conditions, namely high temperatures and vacuum in the process chamber, are of special interest when using titanium alloys like Ti-6Al-4V (Ref 22). The high temperature reduces the thermal gradient during the building process, thus reducing residual stresses (Ref 22), and the vacuum prevents the highly reactive material (Ref 23) from oxidations. Therefore, it is possible to additively build specimens with similar properties to wrought materials (Ref 24). Disadvantages of using EB in the PBF process are rough surfaces (Ref 21) and the long production times as results of vacuum and high building temperatures resulting in long process times (Ref 22). PBF-EB is used in (Ref 22) to build additively manufactured elements (AME) on sheet metal, both made of Ti-6Al-4V, to create hybrid parts with different granular structures in each component. Because of the high importance of the connection strength between the AM structure and the sheet metal base, the authors in (Ref 21) designed tools for investigations regarding the shear and tensile strength of joints of hybrid parts, schematically shown in Fig. 2.

They found the transition area to be critical for the joint strength and especially in tensile testing, high surface roughness deteriorates the joint strength due to their crack initiating and stress concentrating effect (Ref 21). This influence is found for PBF-LB as well in (Ref 25). The feasibility of building AMEs on sheet metal using PBF-LB, as well as the joint strength is investigated in (Ref 25). For PBF-LB, argon is used instead of a vacuum atmosphere to prevent oxidation, which creates brittle oxide phases reducing the joint strength (Ref 25). By using adequate strategies, namely sacrificial structures to react with the remaining oxygen, and system adjustments, it is possible to reduce the oxidation and thus the brittle phases (Ref 25). A next step is performed in (Ref 5), in which PBF-LB is used to build up structures on already formed sheets. Ti-6Al-4V sheets are deep drawn and used as substrate plates to build up cylindrical functional elements with PFB-LB of the same material (Ref 5). Due to the previous forming step, a special clamping device is needed to build up structures on the sheet (Ref 5). Still, joining defects in the transition area between sheet and AME arise because of the uneven surface of the formed sheet (Ref 5). In combination with residual stresses created during the PBF process, these defects can result in cracks reducing the joint strength of hybrid parts with formed
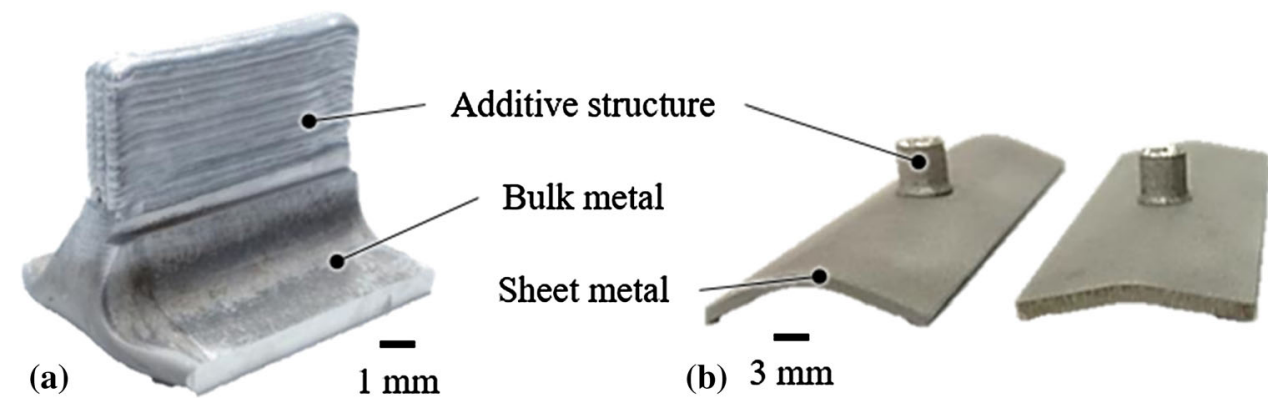

(b) $3 \mathrm{~mm}$

Fig. 1 Hybrid parts made of (a) bulk metal forming and directed energy deposition (Ref 6) and (b) sheet metal forming and laser-based powder bed fusion (Ref 7) 


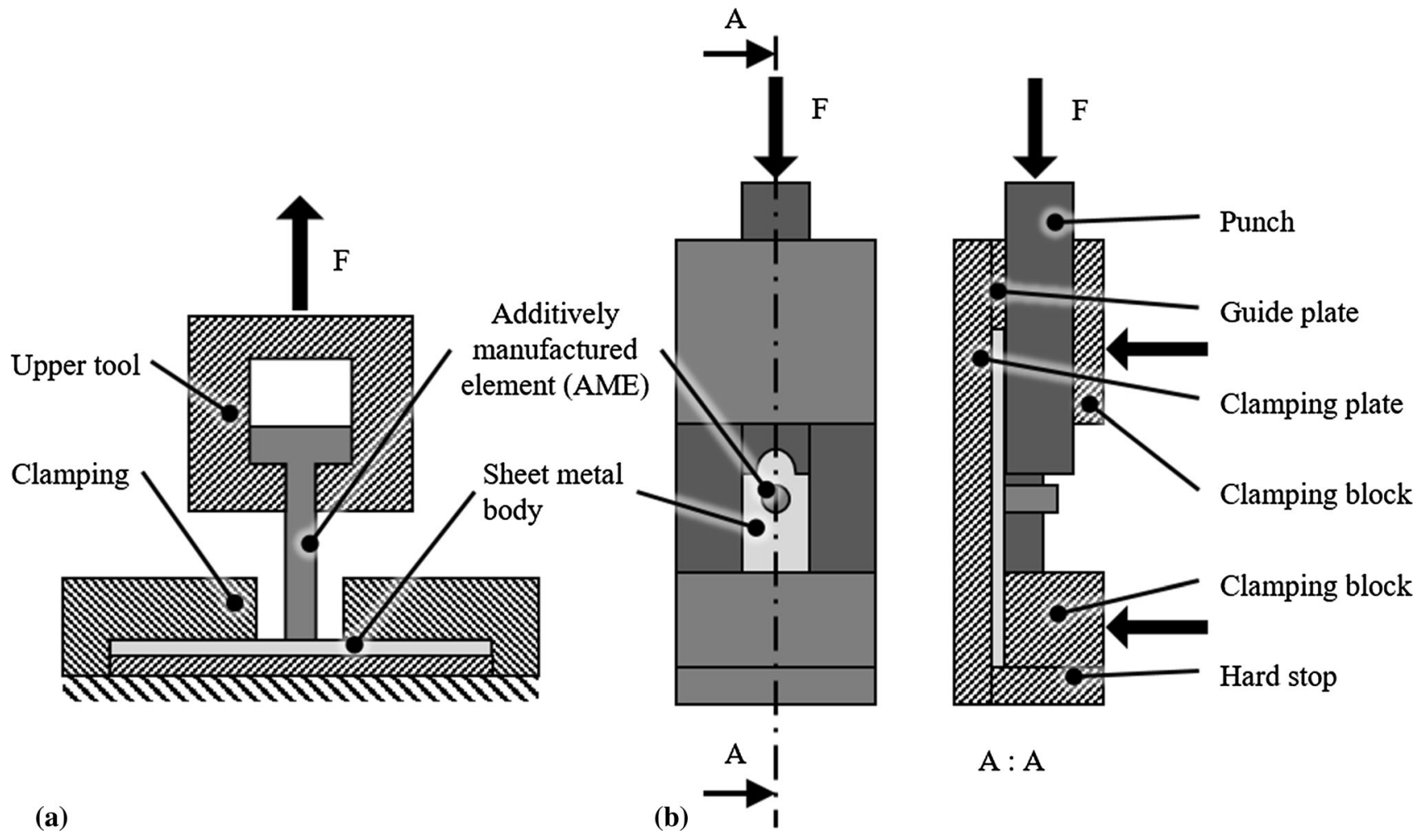

Fig. 2 Schematic representation of setups for testing the tensile (a) and shear (b) bonding strength of hybrid parts according to (Ref 22)
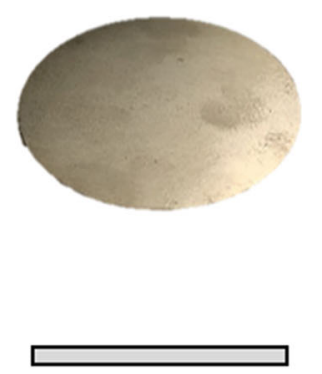

Sheet metal body

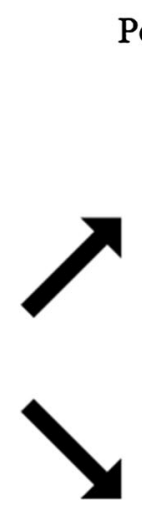

Forming
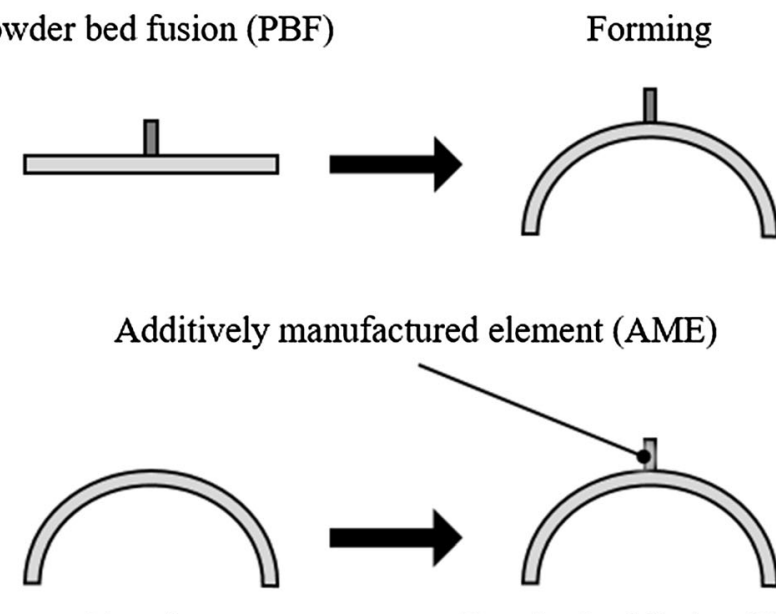

Additively manufactured element (AME)

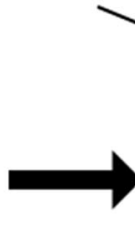

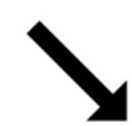
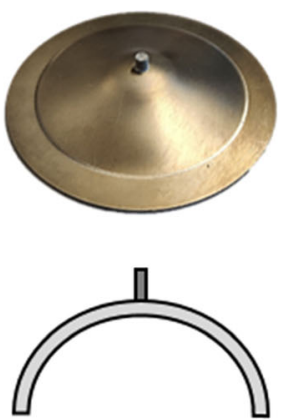

Hybrid Part

Fig. 3 Different processing routes for the manufacturing of hybrid parts including sheet metal and AM components according to (Ref 7)

sheet compared to hybrid parts with conventional sheet (Ref 5). However, a heat treatment of $2 \mathrm{~h}$ at $850{ }^{\circ} \mathrm{C}$ as it is recommended in (Ref 26) for AM parts made of Ti-6Al-4V, as well as a fillet radius at the transition area are found to increase the joint strength of AMEs on sheet material (Ref 5). The forming of hybrid parts is investigated in (Ref 27), in which the application-oriented stress state of bending is applied to hybrid parts. An AME is built on sheet metal, both made of Ti-6Al-4V, and bent at elevated temperatures using a specially designed tool (Ref 27). This tool is qualified and used for conventional sheets and hybrid parts as well (Ref 27). The experiments with hybrid parts are expected to have a higher resistance to bending due to a stiffness increased by the AME, but the resulting forces prove the opposite, whereas only minimal punch displacement can be achieved without failure in terms of cracking in the transition area ( Ref 27). The reason for this is mentioned to be the porous structure of the AME having a stress concentrating effect on the tensile forces acting on the transition area (Ref 27). Both sequences (Fig. 3) can be used to create formed hybrid parts, but the first process always influences the second process (Ref 27). 
Thus, the influence of the sequence of warm bending and PBF is investigated in (Ref 28). An prior AM process reduces the formability in terms of bending of the hybrid parts due to the stiffening effect of the AME and the premature failure of the parts (Ref 28). Whereas a subsequent AM process is having defects in the transition zone because of the building on a curved surface (Ref 28). Additionally, AM on formed parts is only possible until a difference of height in building direction is reached, which cannot be coped with by system technologies like special clamping devices and flexible coaters anymore (Ref 28). Nevertheless, the shear strength is not significantly influenced by the sequence of the processes if parts are heat treated (Ref 28). Besides the sequence of the processes, the position of the AME on the sheet during the bending operation can vary. Therefore, in (Ref 29), the influence of AMEs being placed in the compressive or tension zone of the bending process is investigated. Results show a decrease in shear strength for formed hybrid parts compared to unformed ones, whereas the shear strength is lower for AMEs placed in the compressive zone than in the tension zone (Ref 29). The lower joint strength of formed hybrid parts is explained by the strains induced during the bending operation and the resulting crack initiation (Ref 29). Additionally, Papke et al. found the different microstructures in each component of the hybrid parts to have individual mechanical properties (Ref 29). The highest hardness is located in the AME, which decreases in the heat affected zone (HAZ) and is lowest in the sheet component (Ref 29). Thus, first investigations on stretch forming of hybrid parts include numerical simulations with adapted material modelling (Ref 30). The HAZ increases with decreasing sheet thickness because of the low thermal conductivity of titanium (Ref 16) creating a heat accumulation (Ref 29). Despite the higher hardness of the HAZ, parts with a smaller HAZ, as they are found for sheets with higher thickness, show a higher shear strength (Ref 29). With that in mind, the influence of sheet thickness and heat treatment temperatures is investigated in (Ref 31) in terms of tensile joint strength. The results found for shear strength in (Ref 29) can be applied to tensile strength (Ref 31). A higher sheet thickness leads to a higher joint strength, as well as a heat treatment at $850^{\circ} \mathrm{C}(\operatorname{Ref} 31)$. The heat treatment smoothens gradient of mechanical properties over the components of the hybrid part, thus increasing the strength of the connection (Ref 31). To summarize, investigations on hybrid parts made with sheet metal forming and PBF include the following combinations:

- PBF on conventional sheet,

- PBF on flat surface of deep drawn sheet,

- PBF on curved surface of bent sheet,

- Bending of hybrid parts with AM structures made with PBF and

- Stretch forming of hybrid parts with AM structures made with PBF.

Because of its high importance, the joint strength of hybrid parts is tested for tensile and shear loads. Besides the factors sheet thickness, heat treatments, PBF parameters and forming parameters different stress states are present. Therefore, the different stress states acting on hybrid parts are compared and the influence of an AME is investigated in this paper.

\section{Analysis of Hybrid Parts in the Stress States of Selected Forming Operations}

Compared to conventional sheet metal, hybrid parts combining sheet metal and additive structure have a reduced formability. The reason for this is expected to be the additively manufactured structure leading to an earlier failure of the part in different forming operations. To be more precise, it is assumed that additively manufactured structures on sheet metal have a stress concentrating effect and thus increasing necking and earlier material failure. This has to be proven. Therefore, the stress states of commonly used sheet metal forming processes deep drawing, bending and stretch forming are investigated for conventional sheet and hybrid parts, shown in Fig. 4.

\subsection{Methodology}

Hybrid parts consisting of Ti-6Al-4V sheet and AME are formed at $400{ }^{\circ} \mathrm{C}$ with three different forming operations. The stress state of the three processes is elaborated for the area, in which the AME is placed. The processes are modelled using a numerical simulation for conventional sheet and hybrid parts. The model is validated in pre-investigations (Ref 30) based on the parts geometry and sheet thickness. Differences found in terms of stresses are used to investigate the influence of additively manufactured structures on the formability of hybrid parts. The setup of the numerical simulation used is presented in (Ref 30). Different material properties can be addressed to each of the components of the hybrid part. Due to their differences in mechanical properties, different material modes are used for sheet metal and additively manufactured material to have a more precise approach. The software used for the numerical simulation is LS-Dyna by LSTC including LSPrePost v.4.7.0 and the solver MPP Double R11.1. The tools, namely punch, binder and die, are modelled using rigid (020RIGID) Belytschko-Tsay shell elements (ELFORM =2). For the AME, constant stress solid elements $(E L F O R M=1)$ and the material model 024-PIECEWISE_LINEAR_PLASTICITY are used. The sheet is simulated using fully integrated shell elements (ELFORM 16) with seven integration points along the sheet thickness and the anisotropic elastoplastic material model 233-CAZACU_BARLAT. Yield criteria and flow curves are determined by experiments. The flow curves are approximated and extrapolated using the model of Nemat-Nasser (Ref 32) and can be found in (Ref 30). For all simulations, no failure criterion is used. Concerning boundary conditions, constraints are applied as follows. For the bending simulation (Fig. 5b), the punch is constrained in all three directions $(\mathrm{CMO}=1$; $\mathrm{CON} 1=7 ; \mathrm{CON} 2=7$ ). The die is only allowed to move in $z$-direction $(\mathrm{CMO}=1 ; \quad \mathrm{CON} 1=4 ; \quad \mathrm{CON} 2=7)$, which is enabled by PRESCRIBED_MOTION_RIGID with a translational motion in $z$-direction ( $(\mathrm{DOF}=3$ ). The specimen is fixed in $y$-direction on one of the short edges (Fig. 5e) using a node set and the corresponding boundary SPC_SET with DOFY $=1$, remaining constraints are set to " 0 ". The approach for the deep drawing (Fig. 5a) and stretch forming (Fig. 5c) simulation is similar. The die is constrained in all directions $(\mathrm{CMO}=1$; $\mathrm{CON} 1=7 ; \mathrm{CON} 2=7)$, the binder and punch can only move in $z$-direction $(\mathrm{CMO}=1 ; \mathrm{CON} 1=4$; $\mathrm{CON} 2=7)$. The binder force and the punch displacement are applied with PRESCRIBED_MOTION_RIGID and DOF $=3$. Since the deep drawing and stretch forming operations are modelled using only a 
(a) Deep drawing

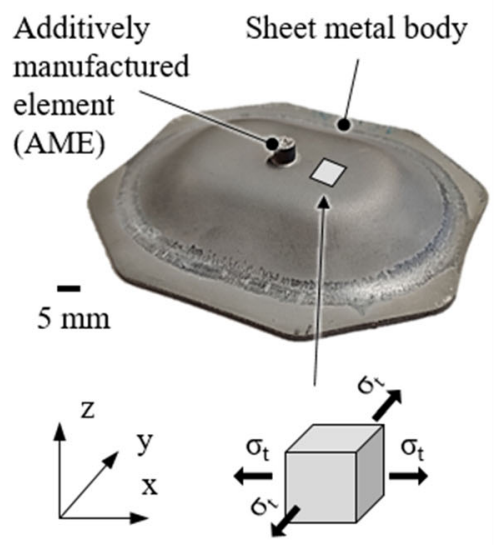

Biaxial tension in plane of sheet

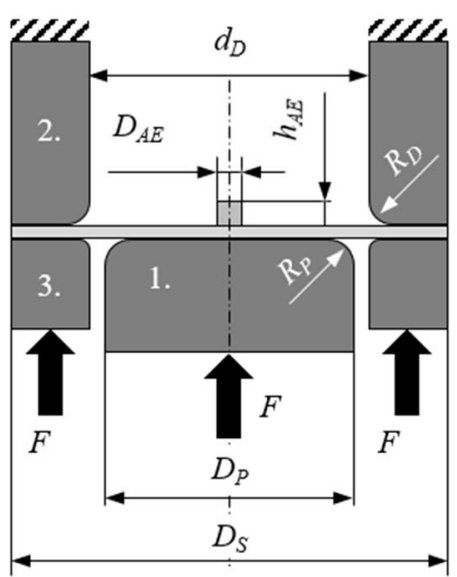

1. Punch

2. Die

3. Binder (b) Bending

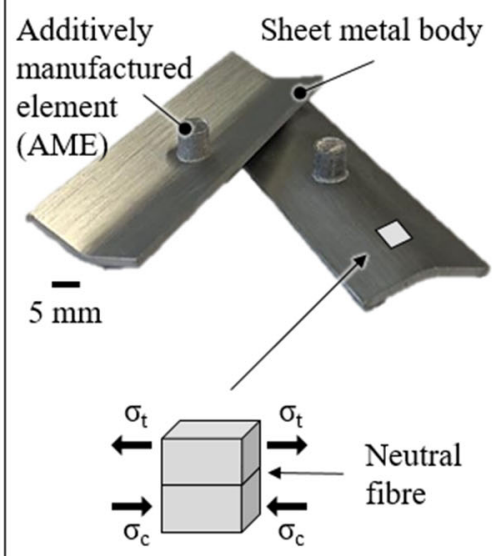

Bending momentum around neutral fibre including tension above and compression beneath

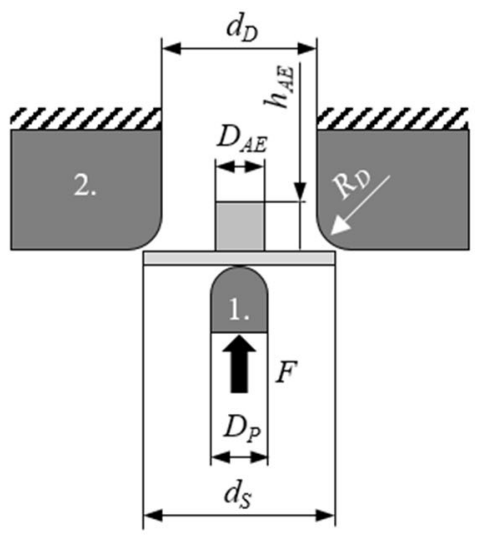

1. Punch

2. Die (c) Stretch forming

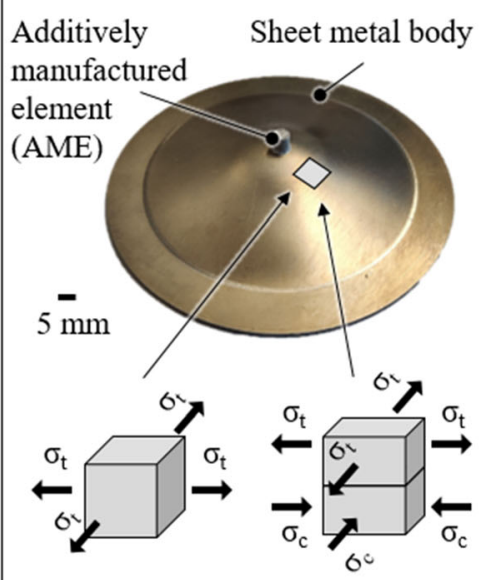

Biaxial tension in plane of sheet + bending momentum in two directions including tension above neutral fibre and compression beneath it

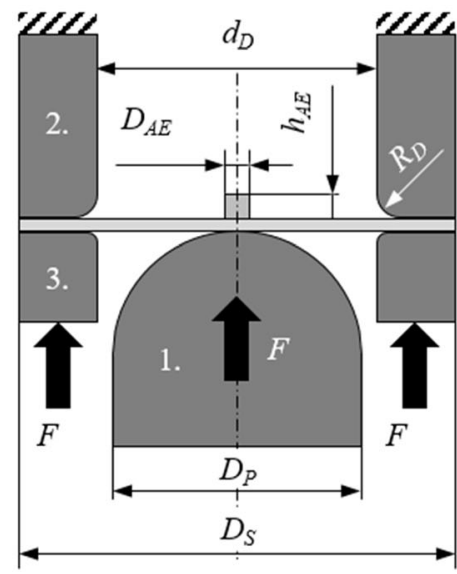

$\begin{array}{ll}\text { 1. } & \text { Punch } \\ \text { 2. Die } \\ \text { 3. }\end{array}$

Fig. 4 Investigated forming operations for Ti-6Al-4V hybrid parts consisting of sheet metal and additively manufactured elements

quarter, SPC SETs are applied to the nodes on the $x$ - and $y$ edges (Fig. $5 \bar{d}$ and $\mathrm{f}$ ). The nodes on the edge in $x$-direction are free to move in $y$ - and $z$-direction and to rotate around the $x$ axis. The nodes on the edge facing the $y$-direction are able to move in $x$ - and $z$-direction and rotate around the $y$-axis. For all forming simulations shown, the connection between AME and sheet is done the same way. Both parts share common nodes on the bottom of the AME, but have their own elements created between them (Ref 30$)$. This connection can be compared to a tied-constraint contact. Stresses and strains are analyzed within these simulations for sheets with and without AME. The detected differences are then used to determine the influence of the AME on the formability and the impact of the stress state on formability is derived. The areas of high stresses in the simulation indicate critical areas. Therefore, microsections are taken from hybrid parts after forming to investigate the metallographic structure of critical part areas.

\subsection{Deep Drawing}

The process of deep drawing includes different stress states over individual part areas. In the area of the bottom of the cup, biaxial tensile forces are acting in the plane of the sheet and compressive forces perpendicular to it are applied by the punch. These stresses are rather low, compared to the remaining ones. At the radius of the punch, bending forces are applied to the sheet metal. The wall of the cup is formed by tensile stresses in radial and tangential direction. At the radius of the die, the sheet is bent twice before the flange is loaded with tensile stresses in radial direction and compressive stresses in tangential direction and direction of the sheet thickness. An application-related position for AMEs is feasible in the area of the bottom of the cup (Ref 33).

Thus, the influence of the stress state in the bottom of the cup on AMEs is investigated in the following. The resulting stresses in the numerical deep drawing simulation are shown in 


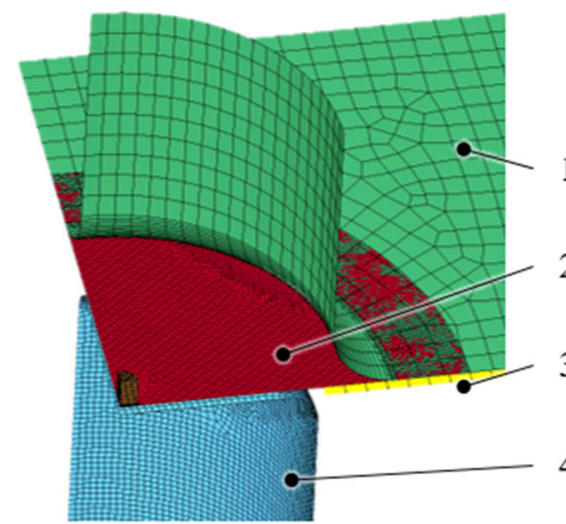

(a)

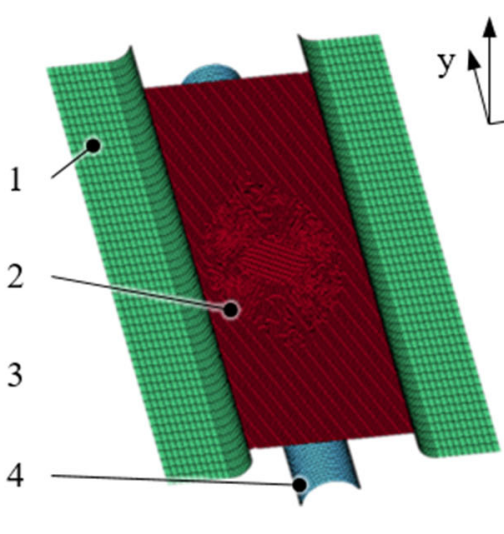

(b)

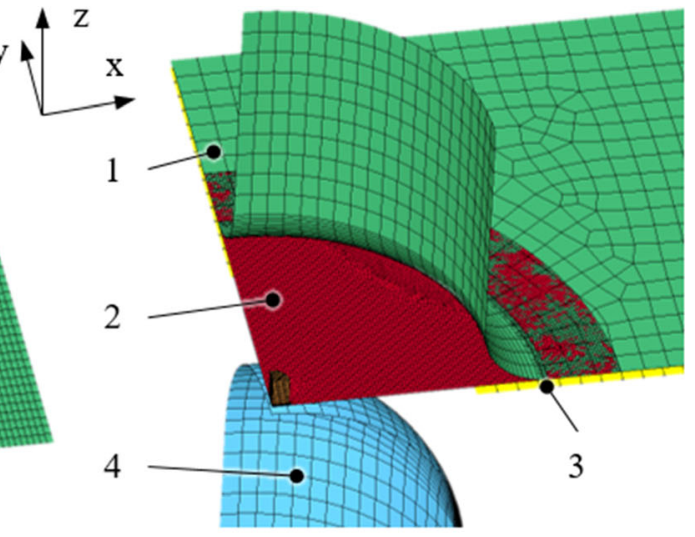

(c)

1 -Die, 2 - Specimen, 3 - Binder, 4 - Punch

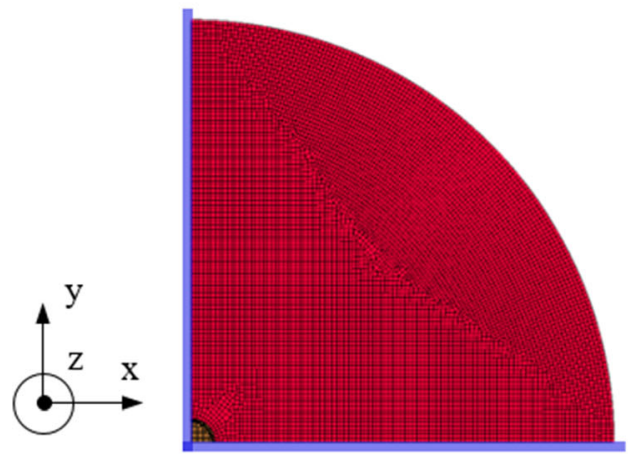

(d)

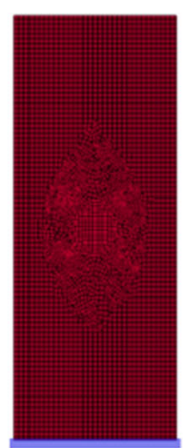

(e)

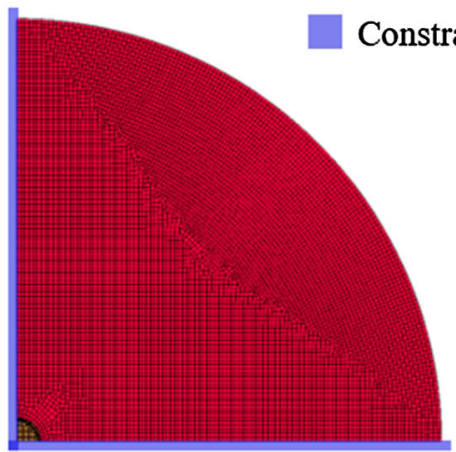

(f)

Fig. 5 Numerical setup of the forming processes (a) deep drawing, (b) bending and (c) stretch forming with highlighted nodes used for the boundary conditions (d-f)

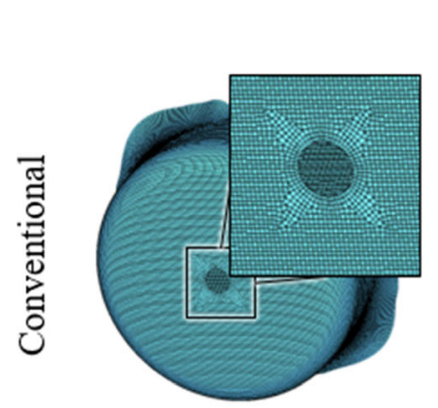

(a)

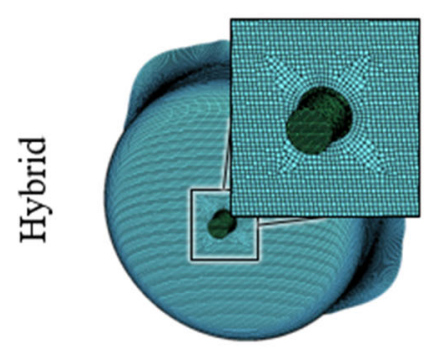

(e)

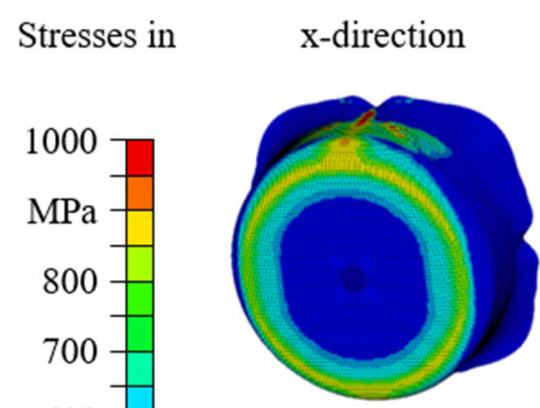

(b)

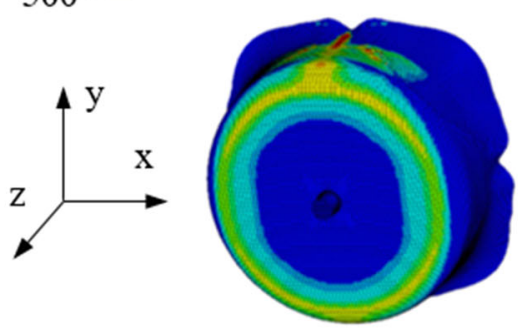

(f)

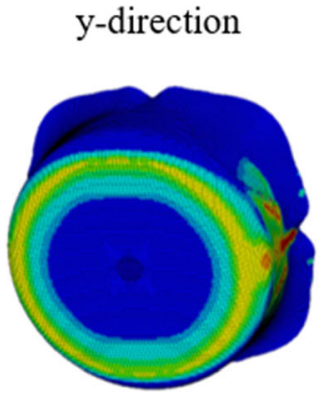

(c)

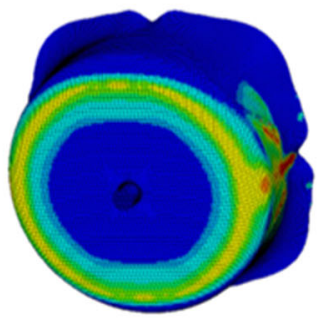

(g) z-direction

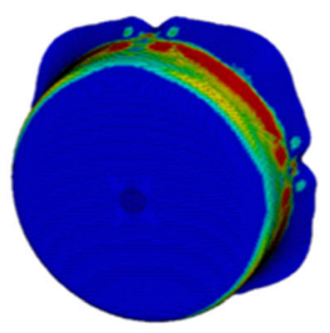

(d)

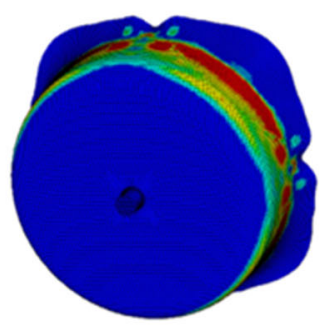

(h)

Ti-6Al-4V; $T=400{ }^{\circ} \mathrm{C} ; \mu=0.2 ; t=1.5 \mathrm{~mm} ; d=15 \mathrm{~mm} ; D_{S}=105 \mathrm{~mm} ; D_{P}=60 \mathrm{~mm} ; R_{P}=10 \mathrm{~mm}$; $R_{D}=10 \mathrm{~mm} ; d_{A E}=5 \mathrm{~mm} ; h_{A E}=5 \mathrm{~mm}$

Fig. 6 Resulting stresses of numerical deep drawing simulations for conventional sheet (a-d) and hybrid part (e-h) made of Ti-6Al-4V 
Fig. 6 for conventional sheet (a-d) and hybrid part (e-h). AMEs placed at the bottom of a deep drawn cup are loaded with tensile stresses in two directions within in the plane of the sheet and the compressive stresses due to the punch displacement. Depending on the shape of the punch, the arising stresses are comparably low, since the main forming zone is not located in the bottom of the cup.

Only towards the punch radius, the stresses increase. Therefore, this is the most critical area concerning fracture due to thickness reduction. The AME on the other hand is placed in the middle of the bottom. At this position only minimal stresses are found. Thus, the presence of an AME has a low influence on the formability and the loads acting on it are minimal. Another reason assumed for the low influence is the small size of the AME compared to the formed cup. Therefore, the forming of hybrid parts to manufacture cups with additive structures at the bottom seems as feasible as building additive structures on already formed cups. In the investigated case, the bottom of the cup is flat and thus an AM process would seem possible.

\subsection{Bending}

The bending process is, in ideal case, characterized by a bending momentum without lateral forces leading to tensile stresses above and compressive stresses below the neutral fiber in the plane of the metal sheet (Ref 33). Both stresses increase with the distance to the neutral fiber (Ref 33$)$. Therefore, the bending specimen has a tension and a compression zone over the sheet thickness. The bending line is assumed to be a circular arc and the sheet thickness stays constant (Ref 33). In reality, the bending process includes lateral forces, a reduction of sheet thickness and the bending line is moved towards the compression zone (Ref 33$)$. Whether the AME is placed in the tension or the compressive zone of bending specimens, the loading at the position is much higher compared to the deep drawing process. Therefore, the influence of the AME on the stress distribution is expected to be higher than in deep drawing, because of the stress state and geometrical relations of AME and size of forming zone. For the bending process, the AME has a much higher diameter in relation to the remaining part compared to the deep drawing process, which is found to be stress increasing in (Ref 30). The results of the numerical bending process of a conventional sheet and the hybrid part are illustrated in Fig. 7 in terms of stresses.

It can be concluded that the AME leads to tensile stress concentrations in $x$-direction in the area of transition, but along the specimen in $y$-direction as well, on the parts top surface. As expected, this is found for the AME being placed in tension zone but also for the compressive zone. Regardless of the position of the AME-tension or compressive zone- the mere presence leads to tensile stress concentrations and thus increase of the probability of a material failure. Furthermore, concentrations of compressive stresses are found at the bottom of the hybrid parts. In both cases, the tensile stresses at the top side of the part are more critical in terms of failure, which can be seen in the results of the forming experiments for an AME on the tension zone, Fig. 8, and the compressive zone, Fig. 9.

The location of the highest stresses in the numerical simulation fits to the point of fracture visible in the microsections for additive structures in the tensile zone. This proves the applicability of the simulation and therefore the influence of the additive structure on the forming process. For conventional parts, there are lower stresses in the simulation and no fracture visible in the microsections with the same process parameters used for hybrid parts. Consequently, it can be concluded that positioning an AME in a tensile stressed area leads to a stress concentration and thus a deterioration of the process performance. The AME itself is mainly loaded at the radius at the transition area with tensile stresses. Due to the reduced

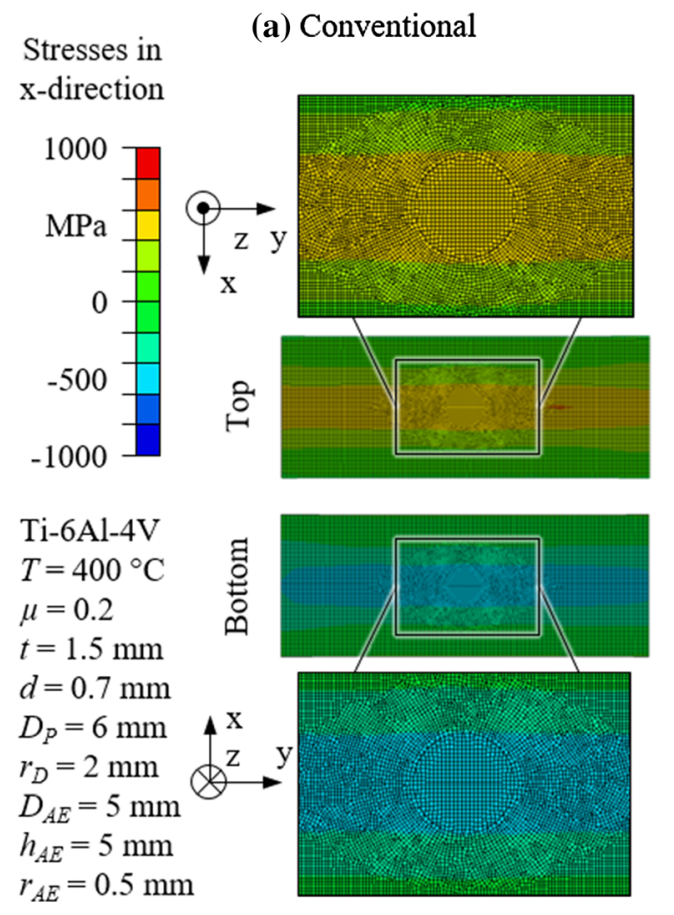

(b) Hybrid
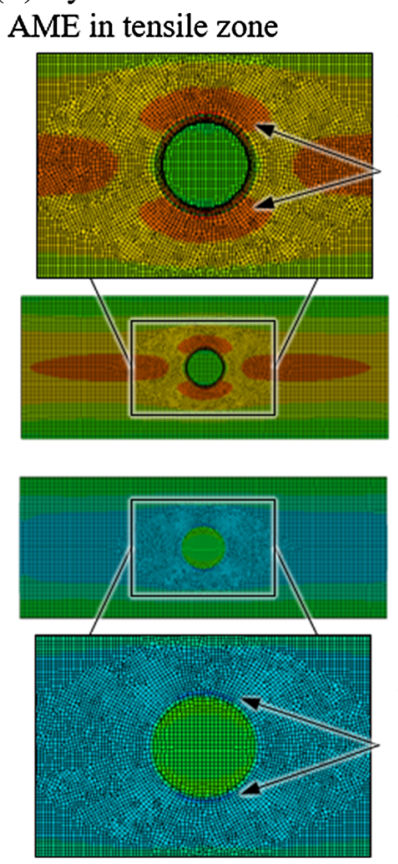

(c) Hybrid
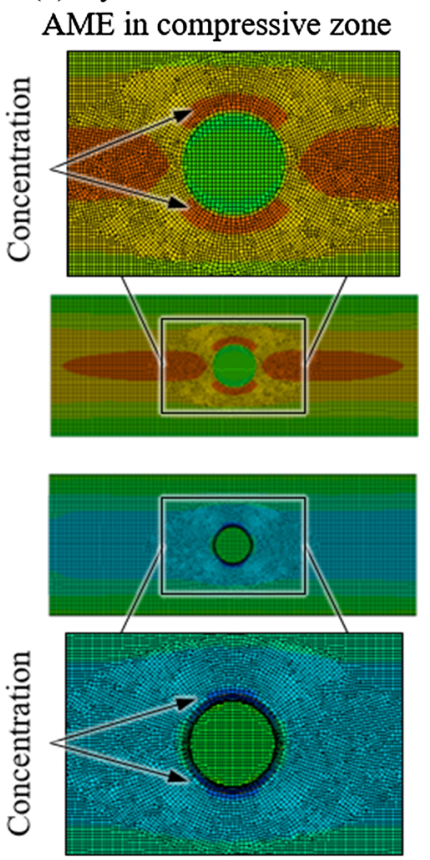

Fig. 7 Resulting stresses in $x$-direction of numerical bending simulations for conventional sheet (a) and hybrid parts $(b+c)$ made of Ti-6Al-4V 


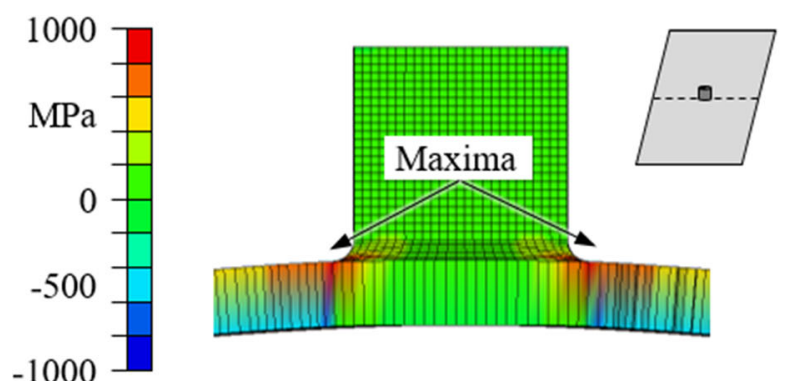

(a)

$$
\stackrel{\mathrm{z}}{\mathrm{y}} \mathrm{x} \quad \begin{aligned}
& \text { Ti-6Al-4V; } T=400{ }^{\circ} \mathrm{C} ; \mu(\text { Simulation })=0.2 ; t=1.5 \mathrm{~mm} ; d=0.7 \mathrm{~mm} ; D_{P}=6 \mathrm{~mm} ; \\
& r_{D}=2 \mathrm{~mm} ; D_{A E}=5 \mathrm{~mm} ; h_{A E}=5 \mathrm{~mm} ; r_{A E}=0.5 \mathrm{~mm}
\end{aligned}
$$

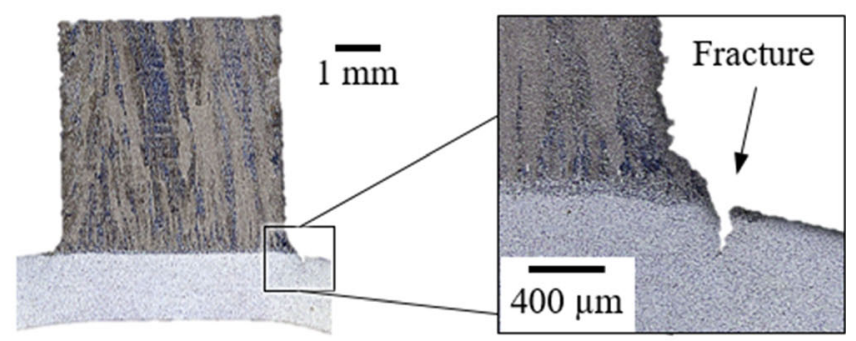

(b)

(c)

Fig. 8 Comparison between the resulting stresses in $x$-direction in the numerical bending process (a) and the material failure of physically tested (b) Ti-6Al-4V hybrid part with additive structure in the tension zone

\section{Stresses in $\mathrm{x}$-direction}

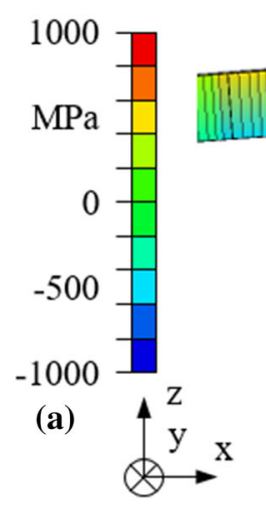

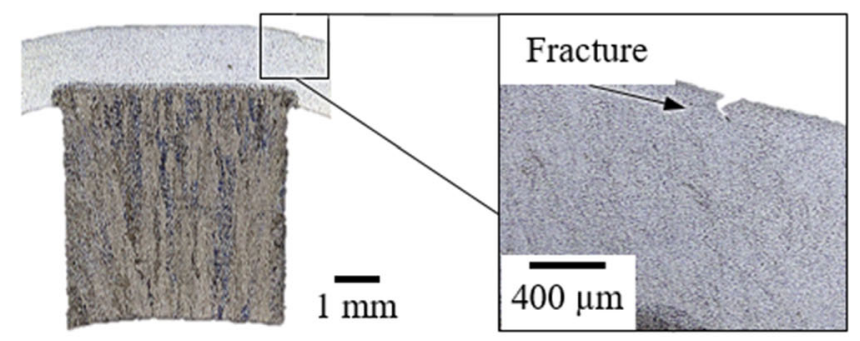

(b) (c)

Ti-6Al-4V; $T=400^{\circ} \mathrm{C} ; \mu$ (Simulation) $=0.2 ; t=1.5 \mathrm{~mm} ; d=0.7 \mathrm{~mm} ; D_{P}=6 \mathrm{~mm}$; $r_{D}=2 \mathrm{~mm} ; D_{A E}=5 \mathrm{~mm} ; h_{A E}=5 \mathrm{~mm} ; r_{A E}=0.5 \mathrm{~mm}$

Fig. 9 Comparison between the resulting stresses in $x$-direction in the numerical bending process (a) and the material failure of physically tested (b) Ti-6Al-4V hybrid part with additive structure in the compressive zone

formability of hybrid parts, a manufacturing with the sequence forming followed by AM seems to be more promising in this case.

For the numerical simulation with the AME placed in the compressive zone of the hybrid part, both, tensile and compressive stresses, increase on the respective side. The concentration of compressive stresses is found at the transition area since the material is compressed there. For tensile stresses, the maximum is not found in the middle of the part, as it is for the conventional part, but shifted in $x$-direction. The increased stiffness caused by the additive structure can be a possible reason for this. Therefore, the process is distorted by the AME. The resulting fracture is located in the sheet metal under tension stress at the opposite side of the AME. Hence, even if placed in the zone of compressive stresses, the AME leads to tensile stress concentrations on the tension loaded side and concentrations of compressive stresses on the other side. The stresses acting on the AME in the compressive zone are again mainly found in the radius and the transition area, which does not result in fracture. Therefore, tensile stresses seem to be more crucial than compressive stresses for forming such parts. Due to the geometry of the part and high stresses at the AME, a forming process followed by PBF is challenging. Thus, an alternative
AM processes would be DED or the influence of the AME need to be reduced to increase the formability.

\subsection{Stretch Forming}

The setup of a stretch forming process is similar to the deep drawing process, but the differences are crucial. The sheet is clamped between the binder and the die, but binder forces are kept high in order to prevent material to flow from the flange area unlike for the deep drawing process. The consequence is a reduction of sheet thickness, which is desired in a stretch forming process. Additionally, the shape of stretch forming punches is rather spherical and not flattened as in deep drawing processes. Still there is a biaxial tensile stress state in the plane of the sheet material, but due to the geometry of the punch, an additional bending momentum around the punch can be present. The combination of biaxial stress due to the punch displacement and the tensile stresses at the top of the sheet caused by the bending moment, lead to a higher load in the middle of the part (Ref 33).

The AME is placed in the area of highest stresses, therefore the influence on the formability is expected to be higher compared to the deep drawing process. On the opposite, in relation to the final part, the size of the AME is comparably 


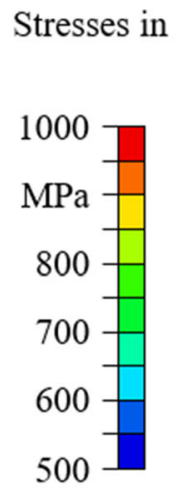

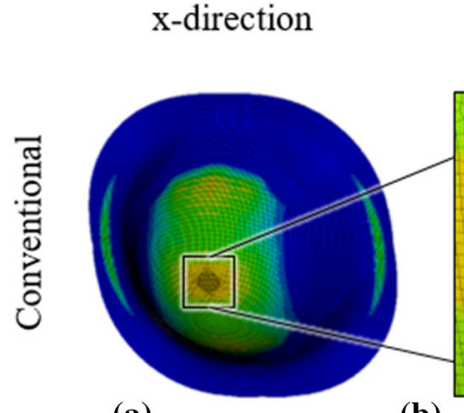

(a)

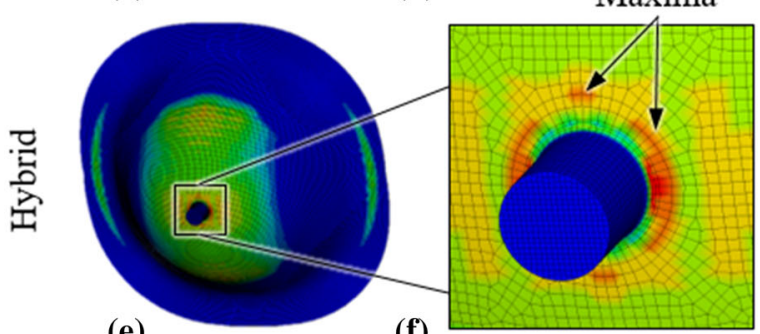

(e)

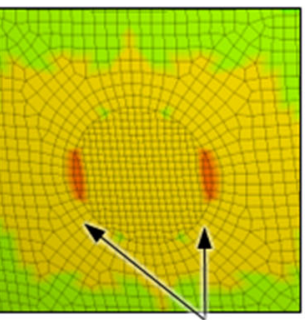

Maxima $\mathrm{y}$-direction

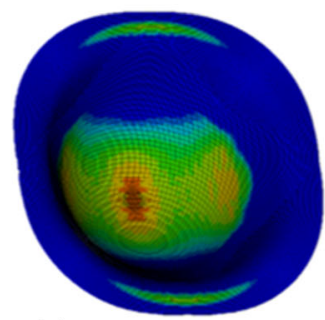

(c)

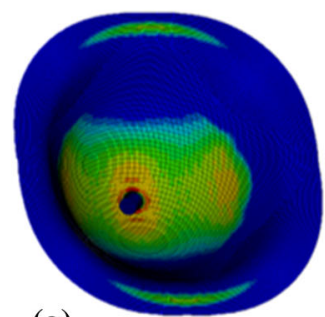

(g)

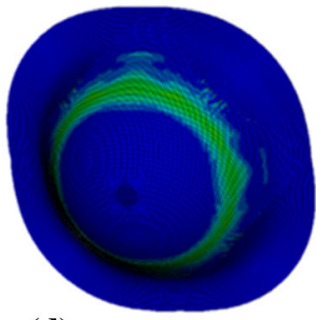

(d)

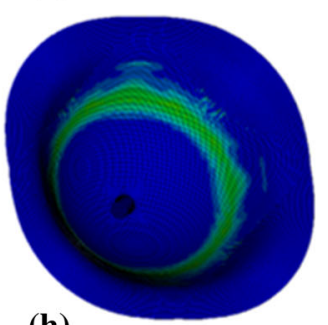

(h)

Ti-6Al-4V; $T=400{ }^{\circ} \mathrm{C} ; \mu=0.2 ; t=1.5 \mathrm{~mm} ; d=15 \mathrm{~mm} ; D_{S}=105 \mathrm{~mm} ; D_{P}=60 \mathrm{~mm} ; r_{P}=10 \mathrm{~mm}$; $r_{D}=10 \mathrm{~mm} ; D_{A E}=5 \mathrm{~mm} ; h_{A E}=5 \mathrm{~mm} ; r_{A E}=0.5 \mathrm{~mm}$

Fig. 10 Resulting stresses of numerical stretch drawing simulations for conventional sheet (a-d) and hybrid part (e-h) made of Ti-6Al-4V

\section{Stresses in $\mathrm{x}$-direction}

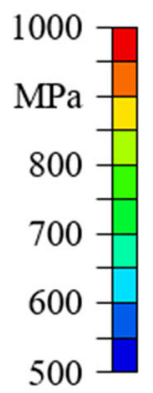

(a)
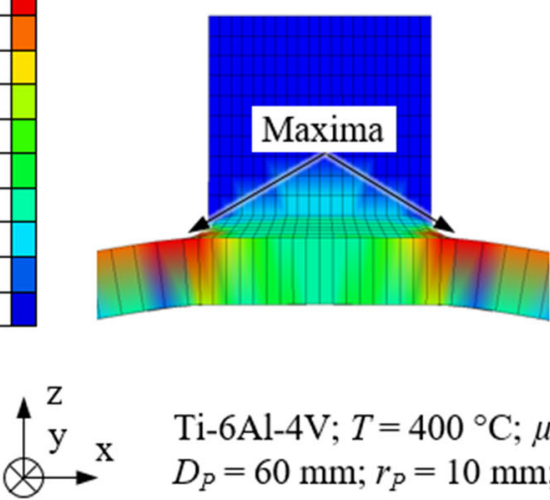

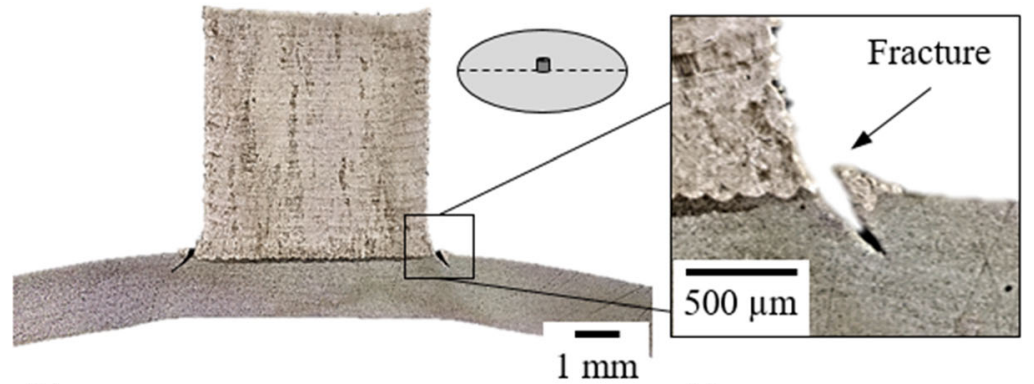

(c)

Fig. 11 Comparison between the resulting stresses in $x$-direction in the numerical stretch forming process (a) and the material failure of physically tested (b) Ti-6Al-4V hybrid part

low, which would benefit the formability. The resulting effect can be seen for the numerical simulation of the stretch forming process for conventional and hybrid parts as well in Fig. 10. The stresses in the plane of the sheet material in the area of the AME are higher compared to the deep drawing process, similar to the bending process. Additionally, stress concentrations are found around the AME, whereas the conventional part has a more even distribution of stresses. Physical forming experiments with hybrid and conventional parts prove this finding. The conventional sheet can be drawn to a depth of $15 \mathrm{~mm}$ without failure, whereas the hybrid part shows small cracks in the transition area Fig. 11. The highest stresses found in the numerical stretch forming process are at the same position, where the physically tested part fails in terms of fracture. This confirms the stress concentrating effect of the AME, which decreases the formability. As mentioned for the bending operation, placing an AME in a tensile loaded area concentrates the stresses at the transition area and favors material failure in terms of fracture. For the bending process, the tensile stresses are one dimensional, and for the stretch forming process, the stress state is biaxial tension. This would explain the effect of the AME despite its smaller size.

The results found would suggest that the manufacturing of stretch formed hybrid parts using a subsequent AM process are favorable. However, the curved geometry can be challenging for powder bed based processes, especially with increasing diameter of AME. With increasing diameter of AME, the difference in building direction, which has to be compensated with system technologies, becomes higher. Since this is only possible up to a certain point, bigger hybrid parts with bigger diameters have to be manufactured with the sequence "forming after AM" and the influence of the AME has to be kept low. 
Regardless of the stress state, in the investigated experimental space, the presence of an AME reduces the formability of hybrid parts for the processes bending and stretch forming by its stress concentrating effect. Nevertheless, some geometries can only be made by PBF followed by forming. In this case, the influence of the AME has to be reduced to a minimum. Since there are some effects that can be addressed, a guideline in the following chapter summarizes advices for the manufacturing of AMEs on sheet metal with intention towards a subsequent forming process.

\section{Conclusion for the Design of Additively Manu- factured Components of Hybrid Parts}

With a subsequent forming process in mind, different aspects of AM processes have to be taken care of. The most important factors found in current research are summed up in the following. As mentioned before, the stiffness of the part increases because of the additional material (Ref 19). This may be beneficial for later applications (Ref 19), but deteriorates the forming process (Ref 28). If possible, geometries should be adapted to the intended forming process and sharp corners, e.g., in transition areas, should be avoided as they have stress concentrating effects (Ref 5). High surface roughness has a stress concentrating effect as well and furthermore are starting points for crack initiation (Ref 21). Thus, the AM process should aim at low surface roughness (Ref 21). Another important aspect is the gradient of mechanical properties between AME and sheet metal body (Ref 31). As a result of the process, residual stresses and microstructural changes lead to a higher strength and lower ductility in the AME (Ref 31). By using adequate PBF parameters and adequate heat treatments, residual stresses can be reduced (Ref 34) and the gradient of mechanical properties can be smoothened.

\section{Conclusion and Outlook}

Due to their beneficial properties, hybrid parts are focus of recent research. Combining AM processes and forming processes is a promising approach, but the interactions are rather complex. Therefore, Ti-6Al-4V hybrid parts made of sheet metal and AM structured made by PBF-LB were investigated in the selected forming processes deep drawing, bending and stretch forming. Numerical simulation of the processes was analyzed with exemplary forming experiments in order to examine the behavior of the hybrid parts and the difference compared to conventional sheet.

The process of deep drawing is least critical in terms of material failure since an AME located on the bottom of the cup is placed in an area of low biaxial stresses. Therefore and because of the flat surface the AME is placed on, deep drawing of hybrid parts can be manufactured using the forming step before and after the AM process. Bending of hybrid parts can be performed with AMEs in the tensile stressed or compressive stressed side of the part. Either way, the stresses were concentrated on each side at the transition area, whereas the tensile stresses are more critical in terms of fracture at the bonding zone. Due to the increased tensile stresses, an earlier fracture arose for hybrid parts compared to conventional sheet material. For the stretch forming process, the biaxial stresses found in deep drawing and the additional bending around the punch created biaxial tensions in the plane of the sheet. Again, the AME concentrated the tensile stresses at the transition area thus decreasing the formability compared to conventional parts. Even though in relation to the formed part, the AME is rather small for the stretch forming process, unlike for the bending specimen, where the AME occupies a high proportion of the sheet. Consequently, a forming operation followed by AM process is favorable, if possible. For geometries, where system technology adjustments cannot cope with the curved surfaces, the influence of the AME has to be reduced in terms of AM process parameters. Current research names residual stresses, gradients in mechanical properties and stress concentrating effects in terms of rough surfaces and sharp transitions as influencing factors on formability of hybrid parts. In this research, the forming process and its resulting stress state have to be added to the list of factors.

Further research will focus on increasing the formability of hybrid parts since geometries like undercuts can only be made by PBF followed by forming or forming followed by DED. Possible fields are included in the processes used, PBF and forming. For example, forming experiments with increased number of AMEs or adjusted AME geometry are of interest, as well as ductility increasing measures during the AM process.

\section{Acknowledgements}

Funded by the Deutsche Forschungsgemeinschaft (DFG, German Research Foundation) - Project-ID 61375930 - SFB 814 “Additive Manufacturing” TP B05.

\section{Funding}

Open Access funding enabled and organized by Projekt DEAL.

Open Access This article is licensed under a Creative Commons Attribution 4.0 International License, which permits use, sharing, adaptation, distribution and reproduction in any medium or format, as long as you give appropriate credit to the original author(s) and the source, provide a link to the Creative Commons licence, and indicate if changes were made. The images or other third party material in this article are included in the article's Creative Commons licence, unless indicated otherwise in a credit line to the material. If material is not included in the article's Creative Commons licence and your intended use is not permitted by statutory regulation or exceeds the permitted use, you will need to obtain permission directly from the copyright holder. To view a copy of this licence, visit http://creativecommons.org/licenses/by/4.0/.

\section{References}

1. D. Brackett, I. Ashcroft, and R. Hague, Topology Optimization for Additive Manufacturing, Proceedings of the Solid Freeform Fabrication Symposium, 2011, p 348-362

2. F. Brückner and C. Leyens, Hybrid Laser Manufacturing, Laser Additive Manufacturing. Materials, Design, Technologies, and Applications. M. Brandt Ed., Elsevier, Amsterdam, 2017 
3. F. Klocke, Manufacturing Processes: 4: Forming, Springer, Berlin, New York, 2013

4. M.D. Bambach, M. Bambach, A. Sviridov and S. Weiss, New Process Chains Involving Additive Manufacturing and Metal Forming-A Chance for Saving Energy?, Procedia Eng., 2017, 207, p 1176-1181

5. B. Ahuja, A. Schaub, M. Karg, R. Schmidt, M. Merklein, and M. Schmidt, High Power Laser Beam Melting of Ti-6Al-4V on Formed Sheet Metal to Achieve Hybrid Structures, Laser 3D Manufacturing II, SPIE LASE, San Francisco, California, United States, Saturday 7 February 2015. SPIE, Bellingham, Washington, 93530X, 2015

6. M.P. Sealy, G. Madireddy, R.E. Williams, P. Rao and M. Toursangsaraki, Hybrid Processes in Additive Manufacturing, J. Manuf. Sci. Eng., 2018, 140(6), p 79

7. B. Lauwers, F. Klocke, A. Klink, A.E. Tekkaya, R. Neugebauer and D. Mcintosh, Hybrid Processes in Manufacturing, CIRP Ann., 2014, 63(2), p 561-583

8. F. Klocke, A. Roderburg and C. Zeppenfeld, Design Methodology for Hybrid Production Processes, Procedia Eng., 2011, 9, p 417-430

9. M.F. Ashby, Materials Selection in Mechanical Design, 3 Aufl. Elsevier Professional, Amsterdam, 2005

10. G. Kickelbick, Introduction to Hybrid Materials, Hybrid Materials. G. Kickelbick Ed., Wiley-VCH Verlag GmbH \& Co. KGaA, Weinheim, Germany, 2006, p 1-48

11. M. Hirtler, A. Jedynak, B. Sydow, A. Sviridov, and M. Bambach, Investigation of Microstructure and Hardness of a Rib Geometry Produced by Metal Forming and Wire-Arc Additive Manufacturing, MATEC Web Conf., 2005, p 190

12. I. Sizova, M. Hirtler, M. Günther, and M. Bambach, Wire-Arc Additive Manufacturing of Pre-forms for Forging of a Ti-6Al-4V Turbine Blade, Proceedings of the 22nd International Esaform Conference on Material Forming: ESAFORM 2019, Vitoria-Gasteiz, Spain, 8-10 May 2019. American Institute of Physics, Melville, 2019, p 150017

13. M. Bambach, I. Sizova, F. Silze and M. Schnick, Hot Workability and Microstructure Evolution of the Nickel-Based Superalloy Inconel 718 Produced by Laser Metal Deposition, J. Alloys Compd., 2018, 740, p 278-287

14. M. Bambach, I. Sizova, J. Szyndler, J. Bennett, G. Hyatt, J. Cao, T Papke and M. Merklein, On the Hot Deformation Behavior of Ti-6Al4V made by Additive Manufacturing, J. Mater. Process. Technol., 2021, 288, p 116840

15. B. Dutta and F.H. Froes Eds., Additive Manufacturing of Titanium Alloys: State of the Art, Challenges, and Opportunities, BH Butterworth-Heinemann an imprint of Elsevier, Amsterdam, Boston, Heidelberg, London, 2016

16. C. Leyens and M. Peters, Titanium and Titanium Alloys: Fundamentals and Applications, Wiley-VCH, Weinheim, Chichester, 2003

17. I. Ünsal, R. Hama-Saleh, A. Sviridov, M. Bambach, A. Weisheit, and J.H. Schleifenbaum, Mechanical Properties of Sheet Metal Components with Local Reinforcement Produced by Additive Manufacturing, Proceedings of the 21st International ESAFORM Conference on Material Forming. ESAFORM 2018: Palermo, Italy, 23-25 April 2018, Palermo, Italy. AIP Publishing, Melville, New York, 2018, p 160028

18. M. Bambach, A. Sviridov, A. Weisheit and J. Schleifenbaum, Case Studies on Local Reinforcement of Sheet Metal Components by Laser Additive Manufacturing, Metals, 2017, 7(4), p 113

19. M. Bambach, A. Sviridov, and A. Weisheit, Stiffness Management of Sheet Metal Parts Using Laser Metal Deposition, Proceedings of the 20th International ESAFORM Conference on Material Forming. ESAFORM 2017: Dublin, Ireland, Brabazon, D., Naher, S., Ahad, I.U., Eds., 26-28 April 2017. AIP Publishing, Melville, New York, 2017, p 080014

20. J.L. Bennett, S.J. Wolff, G. Hyatt, K. Ehmann and J. Cao, Thermal Effect on Clad Dimension for Laser Deposited Inconel 718, J. Manuf. Process., 2017, 28, p 550-557

21. A. Schaub, V. Juechter, R.F. Singer and M. Merklein, Characterization of Hybrid Components Consisting of SEBM Additive Structures and Sheet Metal of Alloy Ti-6Al-4V, KEM, 2014, 611-612, p 609-614
22. V. Juechter, A. Schaub, M. Merklein, and R. Singer, Titanium Metal Sheet Structures of Various Wall Thicknesses with Additional Functional Elements Prepared by Selective Electron Beam Melting in a Powder Bed, Proceedings/5th International Conference on Additive Technologies-ICAT 2014. Vienna, Austria, Drstvenšek, I., Ed., 16-17 October 2014; DAAAM specialised conference. Interesansa-Zavod, Ljubljana, 2014, p 119-122

23. G. Lütjering and J.C. Williams, Titanium, 2nd ed. Springer, Berlin, New York, 2007

24. L.E. Murr, E.V. Esquivel, S.A. Quinones, S.M. Gaytan, M.I. Lopez, E.Y. Martinez, F. Medina, D.H. Hernandez, E. Martinez, J.L. Martinez, S.W. Stafford, D.K. Brown, T. Hoppe, W. Meyers, U. Lindhe and R.B. Wicker, Microstructures and Mechanical Properties of Electron BeamRapid Manufactured Ti-6Al-4V Biomedical Prototypes Compared to Wrought Ti-6Al-4V, Mater. Charact., 2009, 60(2), p 96-105

25. A. Schaub, B. Ahuja, M. Karg, M. Schmidt, and M. Merklein, Fabrication and Characterization of Laser Beam Melted Ti-6Al-4V Geometries on Sheet Metal, Proceedings/DDMC 2014, Fraunhofer Direct Digital Manufacturing Conference, Demmer, A. Ed., 12-13 March 2014, Berlin. Fraunhofer Verlag, Stuttgart, 2014

26. B. Vrancken, L. Thijs, J.-P. Kruth and J. van Humbeeck, Heat Treatment of Ti6Al4V Produced by Selective Laser Melting: Microstructure and Mechanical Properties, J. Alloys Compd., 2012, 541, p 177-185

27. M. Merklein, P. Dubjella, A. Schaub, L. Butzhammer, and M. Schmidt, Interaction of Additive Manufacturing and Forming, 6th International Conference on Additive Technologies-iCAT 2016. Proceedings: Nürnberg, Germany, Drstvenšek, I., Drummer, D., Schmidt, M., Eds., 29-30 November 2016: DAAAM Specialized Conference. Interesansa - zavod, Ljubljana, 2016, p 309-316

28. L. Butzhammer, P. Dubjella, F. Huber, A. Schaub, M. Aumüller, A. Baum, O. Petrunenko, M. Merklein, and M. Schmidt, Experimental Investigation of a Process Chain Combining Sheet Metal Bending and Laser Beam Melting of Ti-6Al-4V, Proceedings of the Lasers in Manufacturing LIM, Munich, Wissenschaftliche Gesellschaft Lasertechnik e.V., Ed., 2017

29. T. Papke, P. Dubjella, L. Butzhammer, F. Huber, O. Petrunenko, D. Klose, M. Schmidt and M. Merklein, Influence of a Bending Operation on the Bonding Strength for Hybrid Parts Made of Ti-6Al-4V, Procedia CIRP, 2018, 74, p 290-294

30. J. Hafenecker, T. Papke, F. Huber, M. Schmidt and M. Merklein, Modelling of Hybrid Parts Made of Ti-6Al-4V Sheets and Additive Manufactured Structures, Production at the Leading Edge of Technology, Vol 26, B.-A. Behrens, A. Brosius, W. Hintze, S. Ihlenfeldt, J.P. Wulfsberg Ed., Springer, Berlin Heidelberg, Berlin, Heidelberg, 2020, p $13-22$

31. T. Papke, F. Huber, G. Geyer, M. Schmidt, and M. Merklein, Characterisation of the Tensile Bonding Strength of Ti-6Al-4V Hybrid Parts Made by Sheet Metal Forming and Laser Beam Melting, Advances in Production Research. Proceedings of the 8th Congress of the German Academic Association for Production Technology (WGP), Aachen, Schmitt, R., Schuh, G., Eds., 19-20 November 2018. Springer International Publishing, Cham, 2019, p 361-370

32. S. Nemat-Nasser, W.-G. Guo, V.F. Nesterenko, S.S. Indrakanti and Y.B. Gu, Dynamic Response of Conventional and Hot Isostatically Pressed Ti-6Al-4V Alloys: Experiments and Modeling, Mech. Mater., 2001, 33, p 425-439

33. K. Lange, Handbook of Metal Forming, 1st ed. Society of Manufacturing Engineers, Dearborn, Mich, 2011

34. F. Huber, T. Papke, M. Kerkien, F. Tost, G. Geyer, M. Merklein and M. Schmidt, Customized Exposure Strategies for Manufacturing Hybrid Parts by Combining Laser Beam Melting and Sheet Metal Forming, $J$. Laser Appl., 2019, 31(2), p 022318

Publisher's Note Springer Nature remains neutral with regard to jurisdictional claims in published maps and institutional affiliations. 